\title{
The role of Thermally Activated Building Systems (TABS) in building energy retrofitting: energy diagnosis and management
}

\author{
Rossana Laera ${ }^{1}$, Inmaculada Martínez Pérez ${ }^{2}$, Luis de Pereda Fernández ${ }^{3}$, \\ Ricardo Tendero Caballero ${ }^{4}$, Francesco Iannone ${ }^{5}$ \\ ${ }^{1}$ ENERES Sustainable Energy Systems, E.T.S.E.M. Universidad Politécnica de Madrid, Madrid, Spain \\ ${ }^{2,4}$ Department of Architectural Constructions, E.T.S.E.M. Universidad Politécnica de Madrid, Madrid, Spain \\ ${ }^{3}$ ENERES Sustainable Energy Systems, Madrid, Spain \\ ${ }^{5}$ DICATECh Politecnico di Bari, Bari, Italy \\ E-mail: ${ }^{1}$ rsn.laera@gmail.com (corresponding author)
}

\begin{abstract}
Thermally Activated Building Systems (TABS) play a major role in building envelope integration. TABS operate at low temperatures, enabling efficient utilization of renewable sources. Moreover, their combination with other building energy systems provides a high degree of dynamic interactivity with users, improving the quality of the indoor thermal environment.

In this research, the efficiency of the technology of active pipe-embedded structures is investigated within its practical application in an existing office building energy retrofit in Spain. Concrete Core Activation (CCA) of the original horizontal structure aims at exploiting its thermal inertial properties and potential storage capability in combination with low-grade energy production systems and devices, such as geothermal heat pumps.

A proper methodology of energy diagnosis is aimed at the optimization of TABS performance in building retrofitting. Significant energy savings could be achieved by applying appropriate solutions, control strategies and corrective actions for TABS. The continuity of energy management and follow-up has been proven necessary to keep high standards in terms of TABS energy performance, targeting the identification of energy saving opportunities for the improvement of energy efficiency.
\end{abstract}

Keywords: Thermally Activated Building Systems (TABS), Concrete Core Activation (CCA), energy efficiency, energy diagnosis, Building Energy Retrofitting.

\section{Introduction}

In a context where "energy efficiency" and "sustainability" are concepts increasingly applied in any production and transformation process, Building Energy Retrofitting is considered one of the most successful strategies regarding energy savings and emission reduction. Recovering, regenerating, renovating and reusing are more sustainable than demolishing existing buildings or realizing new constructions. European Directives and National Energy Efficiency Action Plans are increasingly financing these lines of action, while pushing on the use of renewable energy. The implementation of the European Performance Building Directive (EPBD), based on the strategic lines of the 202020 Climate and Energy Package, promotes interventions aiming at the enhancement of building energy standards. The building sector is, indeed, a major consumer of energy, being responsible for approximately $40 \%$ of energy consumption and $36 \%$ of $\mathrm{CO}_{2}$ emissions in the EU (European Union, 2014). Moreover, according to the International Energy Agency (IEA..., 2012), buildings consume 32\% of global energy.

Energy renovation of existing buildings is an opportunity to improve their energy efficiency, potentially decreasing the EU's total energy consumption by $5-6 \%$ and lowering $\mathrm{CO}_{2}$ emissions by about $5 \%$ (European Commission, n.d.). Reducing the thermal energy demand of buildings, by using passive design, a good insulation etc. allows the utilization of Renewable Energy Sources (RES), that is one of the pursued challenges for attaining the EU 2020 goals (Saheb, Bódis, Szabó, Ossenbrink, \& Panev, 2015). The development of new technologies, the conduction of energy audit (European Union, 2012) and Building Energy Systems are, specifically for tertiary buildings, important means to reach the proposed objective of almost zero energy consumption buildings (Rodriguez-Ubinas et al., 2014). 


\section{The role of TABS in Building Energy Retrofitting}

The building envelope, along with its environmental context, occupancy and technical installation are all part of an integrated energy management system. The need for efficiency redirects the line of action towards basic principles of integration which raise that integrity within the framework of human interaction with the environment through architecture (de Pereda Fernandéz, 2014). In this respect, Thermally Activated Building Systems (TABS) play a significant role as part of the building envelope, performing as both a heating and cooling system, while ensuring thermal comfort.

The key of their usefulness is the "integration" in buildings. This integration is possible not only in new construction processes but also in building energy retrofitting, where the inertial capacity of existing structure can improve as the mass increases, to achieve the thermodynamic balance of the system. The factor that makes these systems efficient is in the thermal potential of the inertial elements that are in existing buildings and their activation (de Pereda Fernandéz, 2014). TABS store and dissipate energy. A building with a high thermal mass can dampen thermal fluctuations, while shifting them over time: this concept coincides with the physical principle of "Thermal Inertia". TABS design is oriented towards the equilibrium in the energy exchange, while mitigating indoor air temperature and reducing load peaks. The storage material is the construction mass of the building itself (Balaras, 1996).

In energy renovation processes, the availability of space with regard to height and volume can acquire an extraordinary value, since the possibility to equip the buildings with inertial systems - integrating floors with 5 or $7 \mathrm{~cm}$ of material with high thermal mass - results in considerable thermal comfort with lower costs and higher efficiency (de Pereda Fernandéz, 2014). Instead of moving large volumes of air, TABS entail a significant reduction in energy loads at the same time that surfaces, existing mass and fluids come into play (de Pereda Fernandéz, 2015). Another advantage is that TABS generally operate at low temperatures, enabling efficient utilization of Renewable Energy Sources (RES) (Figueroa, Cigler, \& Helsen, 2018). When energy production systems from RES, such as geothermal energy, come into play with low demand architecture, this integration contributes to increasing efficiency over time (de Pereda Fernandéz, 2014). Helsen (2016) states that the combination of geothermal heat pumps with TABS represents a kind of "perfect union", provided that the design and the global system is part of a holistic approach.

The thermal response of buildings upgraded with thermoactive systems is slower compared to the performance of active devices. This property allows the consumption of energy in time periods when it is most efficient or costeffective, making TABS more suitable for offices and other buildings which are unoccupied during the night (Balaras, 1996): they can be precooled during off-peak hours, for considerable energy savings and more comfortable indoor conditions. This and other control strategies for TABS are shown by Romaní, de Gracia, and Cabeza (2016) and Schmelas, Feldmann, and Bollin (2017) in their papers.

TABS have not yet been extensively studied with regard to their integration in existing buildings, which is not always feasible and effective. Therefore, the original structure, material configuration and several limitations in execution should be taken into account. During the design process and recovery of existing building elements, the behavior of TABS should be assessed in relation to the storage capacity of all the elements and materials involved in the thermal activation. Moreover, properly conducted optimizing operations after the commissioning of TABS may be essential to minimize thermal discomfort and energy waste, adapting the control parameters to the effective situation in buildings (Gwerder, Todtli, Lehmann, Renggli, \& Dorer, 2007; Lehmann, Dorer, Gwerder, Renggli, \& Tödtli, 2011; Lim, J. H. Song, \& S. Y. Song, 2014; Pfafferott, Doreen, \& Koenigsdorff, 2015; Tödtli, Gwerder, Lehman, Renggli, \& Dorer, 2009). In this respect, proper methodology of energy management and follow-up is necessary to minimize weaknesses and anomalies in TABS operation, with regard to their integration in building renovation. The aim is to maximize TABS efficiency from the thermal activation of existing elements and structures.

\section{Retrofits for energy efficient office buildings: integration of TABS in an office building in Madrid}

The building at C/Apolonio Morales, 29, Madrid (Spain), is an intervention model in the renovation of an office building, in a residential and high-level business area of Madrid (Figure 1). It was built in 1989 and it showed a complete obsolescence in its HVAC (Heating, Ventilating and Air Conditioning) system. Despite being located in a high-quality environmental context, this construction did not take advantage of its potential orientation and passive energy, lacked proper insulation, had low hermetic levels and did not recover energy.

The building was renovated in 2009. The intervention was promoted and executed by Fernandez Molina Obras y Servicios S.A. and designed in its energy concept by ENERES, companies which are active in Madrid in the field of construction and sustainable energy systems. All HVAC systems, internal partitions, façade and walls were eliminated; $95 \%$ of the structure was preserved, since it had a clear thermoactive potential; its envelope and technical systems were renovated. Currently, the building evokes a rectangular prism, including three open-plan floors assigned to office use: two of these are above street level, the other is in the basement.

The comprehensive renovation of the building envelope focused on technological innovation. The first intervention towards energy efficiency was focused on minimizing thermal loss through a careful design of the constructive nodes and reducing insulation discontinuities. The solution, that of a double insulation layer of projected polyurethane 
foam, was specifically designed to minimize thermal bridges. Low-emissivity glass and devices for passive solar control have optimized solar incidences on the glazed surfaces. Extruded aluminum slats act as an anti-radiation barrier on the southeastern façade and, in their closed configuration, reduce thermal loss during the nighttime. A fixed textile shielding, was installed to reduce, by approximately $75 \%$, the solar radiation on the glazed envelope of the stairs shaft. Natural ventilation is ensured through the elevator shaft, which serves as a vertical ventilation channel thanks to its vents and holes.
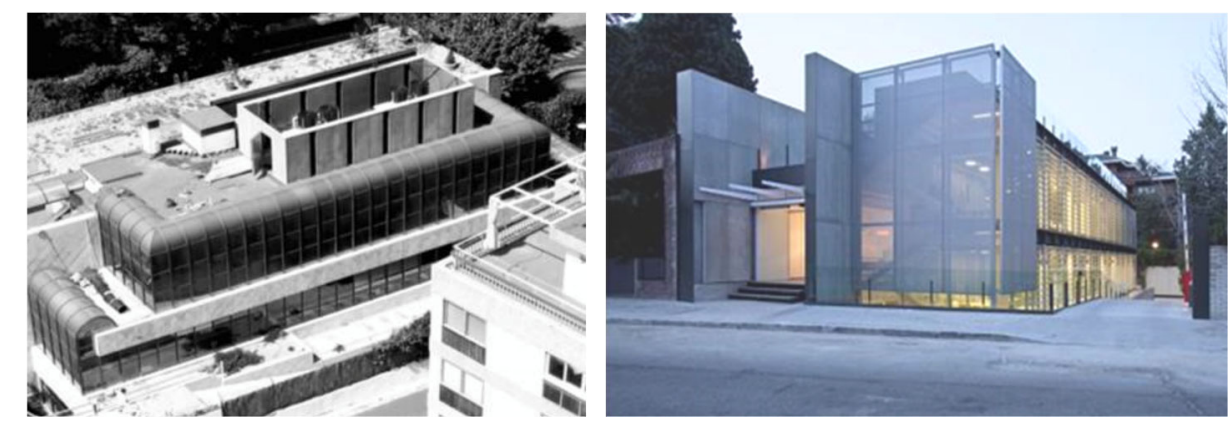

Figure 1. Apolonio Morales 29, Mardid. Before and after renovation (source: ENERES)

The HVAC system combines both the active and passive utilization of solar and geothermal energy through the simultaneous use of inertial devices to transmit the energy to the indoor environment. The primary thermal production system is based on two heat pumps with a geothermal exchange, which allow heat exchange with the ground as a heat and cold source, taking advantage of the stability of temperatures throughout the year, at a certain depth. The construction of a mechanical car park under the back lot of the building resulted in the need for the excavation of a 6-meter deep space, with 10-meter piles, 23 of which were activated as geothermal heat exchangers, producing $25 \%$ of the energy required by the building. The additional $75 \%$ of the energy is obtained by six 100 -meter deep borehole exchangers (Figure 2). This integrated system allows the average building demand both in heating and cooling to be counteracted.
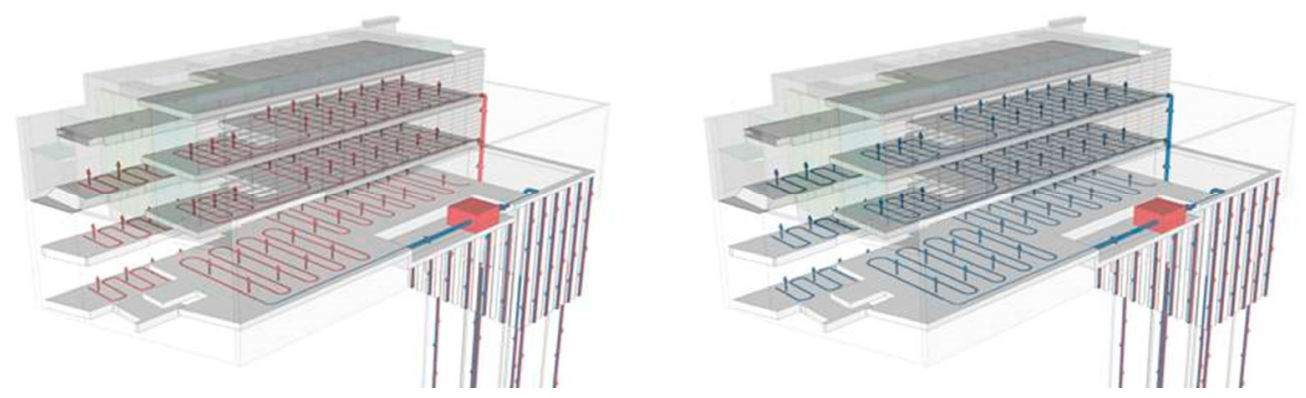

Figure 2. Thermally Activated Building System. Heating and cooling system. Apolonio Morales 29, Madrid (source: IEI Instituto Europeo de Innovación)

The use of the existing structure has conditioned the thermoactivation of the concrete mass using a HDPE circuit in contact with the compression layer of the slabs which, by pouring a thermoconductive mortar (Figure 3), allows the transfer of energy from the fluid to the entire structural mass and to the interior environment.
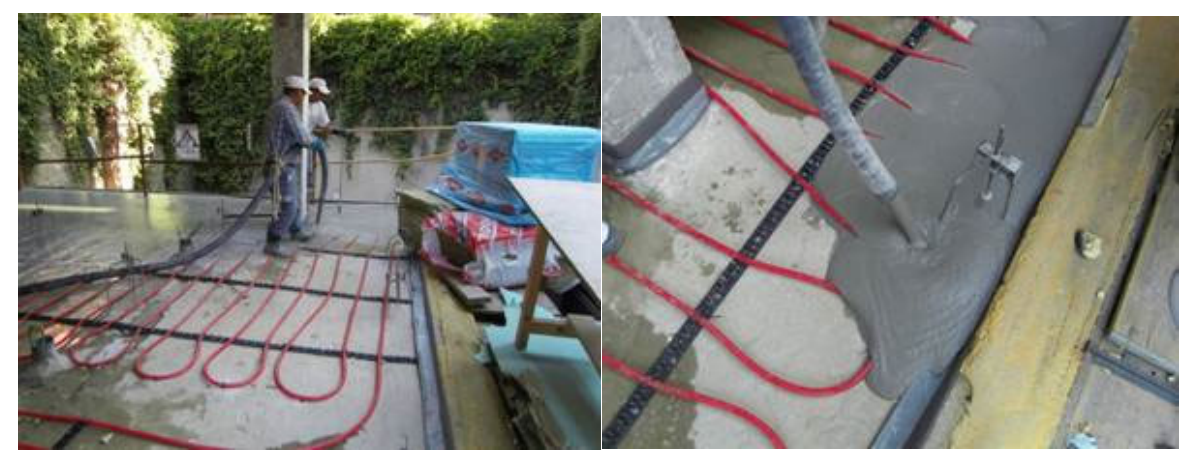

Figure 3. Concrete Core Activation. Apolonio Morales 29, Madrid (source: ENERES) 
The original slab floors, of a double concrete joist, ceramic blocks and a compression layer of $5 \mathrm{~cm}$, were activated with water circulation circuits and a 7-cm supplementary concrete mass to improve the activated mass of around $280 \mathrm{~kg} / \mathrm{m}^{2}$ (ENERES 2009) (Figure 4).

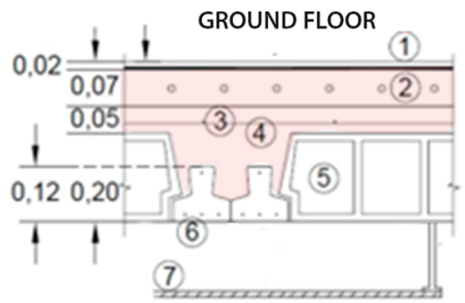

SEMI_BASEMENT FLOOR

\author{
- Tiles + Hollow tiles mixed floor, $\mathrm{h}: 2 \mathrm{~cm}$ \\ 2 - Additional Concrete h: $7 \mathrm{~cm}$ \\ 3 - Anti-Crack Slab Reinforcement Mesh \\ 4 - Reinforced Concrete, h: $5 \mathrm{~cm}$ \\ 5 - Ceramic vault, h: $20 \mathrm{~cm}$ \\ 6 - Doble concrete joists, h: $12 \mathrm{~cm}$ \\ 7 - False ceiling \\ Active thermal mass, $\mathrm{h}: 12 \mathrm{~cm}, \mathrm{M}: 280 \mathrm{~kg} / \mathrm{m}^{2}$
}

Figure 4. Thermal mass activation. Floor section. Apolonio Morales 29, Madrid (source: Self-elaboration)

In support of the primary production system, an Air Handling Unit (AHU), integrated in the roof profile, serves as an auxiliary system to counteract demand peaks with a rapid response. Five solar air collectors are installed on the roof to warm the renovated air that is introduced into the building through the AHU. These panels enable the exploitation of solar radiation, while reducing energy consumption in winter.

\section{TABS operational strategy and management}

Heat-storage technologies and inertial devices should be managed to synchronize thermal energy production and demand (Aydin, Casey, \& Riffat, 2015), while ensuring appropriate thermal comfort conditions. A Building Management System (BMS) acquires data on the effects that TABS generate in their interaction with the environment, and uses that information to integrate their processes of auto-regulation, strategic operation and adjustment to efficiency scenarios. The control system manages the water flow temperature to distributors and adjusts room temperature depending on the relevant setpoints. The pump operating mode [on/off] depends on a PID (Proportional Integral Derivative) controller, which also controls the intermittent operation of zone water circulation pumps. The range of the corresponding setpoint supply-water temperature is calculated based on the external temperature. Additionally, the control system is able to provide information about the opening state of the valves that adjust the flow rate of supply and return water in radiant circuits, depending on the room temperature setpoints. Each floor is characterized by its own setpoints, due to different thermal insulation conditions, orientation and sun exposure that distinguish one floor from another.

Thermoactivated floors perform as radiant elements during the day and accumulators at night. The performance uses the inertia of the building at nighttime, to avoid the continual use of the heat pumps and maximize the advantages of the geothermal exchange system, according to the following operational strategy:

-Operation in winter: at nighttime, geothermal heat pumps run to keep heat in the floors and prevent activation peaks during the following morning.

-Operation in summer: at nighttime, geothermal heat pumps run to cool the slabs so that the building is precooled for the following day; this operation reduces peak power requirements, limiting the AHU operation.

This strategy is more applicable to offices and other buildings which are unoccupied during the night, so that the structure can be cooled with nighttime ventilation, in summer (Velasco Gómez, Andrés Chicote, Rey Martínez, \& Tejero González, 2017). Moreover, this strategy takes advantage of the night rate for electricity: in this way thermal energy is produced when costs are lower and then is stored within the structure, which dissipates it when there is energy demand. This is the reason why two temperature setpoint values are programmable per floor: one is used for daytime, from 8:00 a.m. to 12:00 a.m., the other is operative during the last hours of the night, from 12:00 a.m. to 8:00 a.m.

\section{Integrated operational scenarios}

TABS operational strategies are part of an integrated and more comprehensive set of scenarios, aimed at achieving a great level of comfort and energy savings throughout the year. The control system, indeed, was designed to allow the implementation, on a common frame, of numerous strategies and scenarios, which perform depending on the received information and boundary conditions:

- Winter days: thermal energy stored in floor slabs is released, simultaneously with the solar thermal collection and interception by the southeastern glazed façade. In support of the primary production system, on sunny days, solar air collectors installed on the roof preheat the air injected into the AHU, where heat is exchanged between return and supply air. On cloudy days, the heat pumps heat floors simultaneously with the release of the thermal energy stored in the floor slabs.

- Winter nights: heat pumps pre-heat floors to take advantage of their inertial properties and the night rate; temperature loss is minimized by closing the slats on the southeastern façade. 
-Summer days: aluminum slats act as an anti-radiation barrier on the glazed façade. Heat gains are absorbed and stored in the floor slabs. In the meantime, the heat pumps cool supply fluid and floors. In support of the primary production system, AHU cools supply air, while exchanging heat between return and supply air.

- Summer nights: outdoor conditions are more favorable for free cooling techniques, like natural ventilation, which can be used to remove portions of the heat load. The heat pumps cool floors during the last hours of the night, taking advantage of the night rate.

- Spring and autumn days and nights: the combination of all or a part of the strategies facilitates thermal comfort requirements. Additionally, a plate heat exchanger allows the recovery of the residual cold stored in the ground, which is used when there are small demands of cold in spring and early summer days.

\section{Analysis and diagnosis of the energy performance of TABS}

The control system allows the monitoring of operative parameters and the management of setpoints via a control interface. A proper energy audit and follow-up methodology is applied, with the aim to optimize and improve the building's energy performance, particularly focusing on TABS operation and management. BMS reporting capabilities include all facets of the building HVAC system, concerning weather conditions (temperature, humidity, atmospheric pressure, solar radiation, wind speed, lighting), heating and cooling system operational status (heat pumps status, supply/return temperatures, energy consumption), AHU operational status (fan speed, temperatures, static pressure, damper position), supply/exhaust fan status, floor-by-floor thermostat sensor readings, etc. Through its interface, the control system allows the consultation of historical and real-time data via "Trend charts" generated by Building Operation WorkStation software. The energy manager can analyze these charts to promote strategies to improve the building's energy efficiency or to optimize the control system itself.

\section{Expected and achieved results}

At the design phase, annual electric energy consumption for heating and cooling were estimated in the range of $15-25 \mathrm{kWh} /\left(\mathrm{m}^{2} \mathrm{a}\right)$, that was to say a $76 \%$ energy reduction, comparing to the original building, before the renovation (ENERES, 2009). This estimation is the result of the integrated operation of TABS with various devices, technologies, low-grade resources and control strategies.

Currently, after almost 10 years of exploitation, the highest energy consumption coincides with the HVAC system, representing $67 \%$ of the whole building energy consumption, according to the last energy audit (Gómez, 2017) (Figure 5). This group includes DHW (Domestic Hot Water), submersible electric pumps for drainage and wastewater, exhaust fans and the fire-fighting system, in addition to the use of geothermal heat pumps for heating and cooling, and mechanical ventilation.

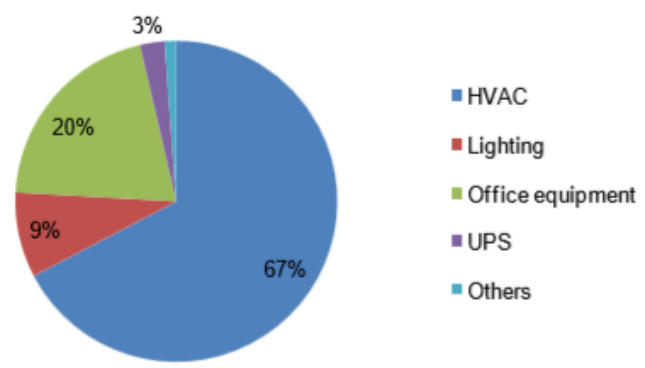

Figure 5. Energy consumption allocation for different types of consumer equipment (source: Gómez, M. Level II Analysis of Apolonio Morales office building, 2017)

The graph in Figure 6, created through the control system interface, updates in real time and shows the evolution of the HVAC energy consumed weekly [kWh/week], throughout a year. It permits the awareness of peak consumption periods, linking them to particular events or operations.

The graph in Figure 7, especially created by correlating parameters characterized by mutual influence, shows the effects of the operational state of the heat pumps [on/off] (red and blue bars), during the first two weeks of July 2018, reflected on the electric energy consumption variation per hour $[\mathrm{kWh} / \mathrm{h}]$ (yellow curve), fluid temperature in the geothermal loop $\left[{ }^{\circ} \mathrm{C}\right]$ (green curve) and fluid temperature in the heating and cooling primary loop $\left[{ }^{\circ} \mathrm{C}\right]$ (red curve). 


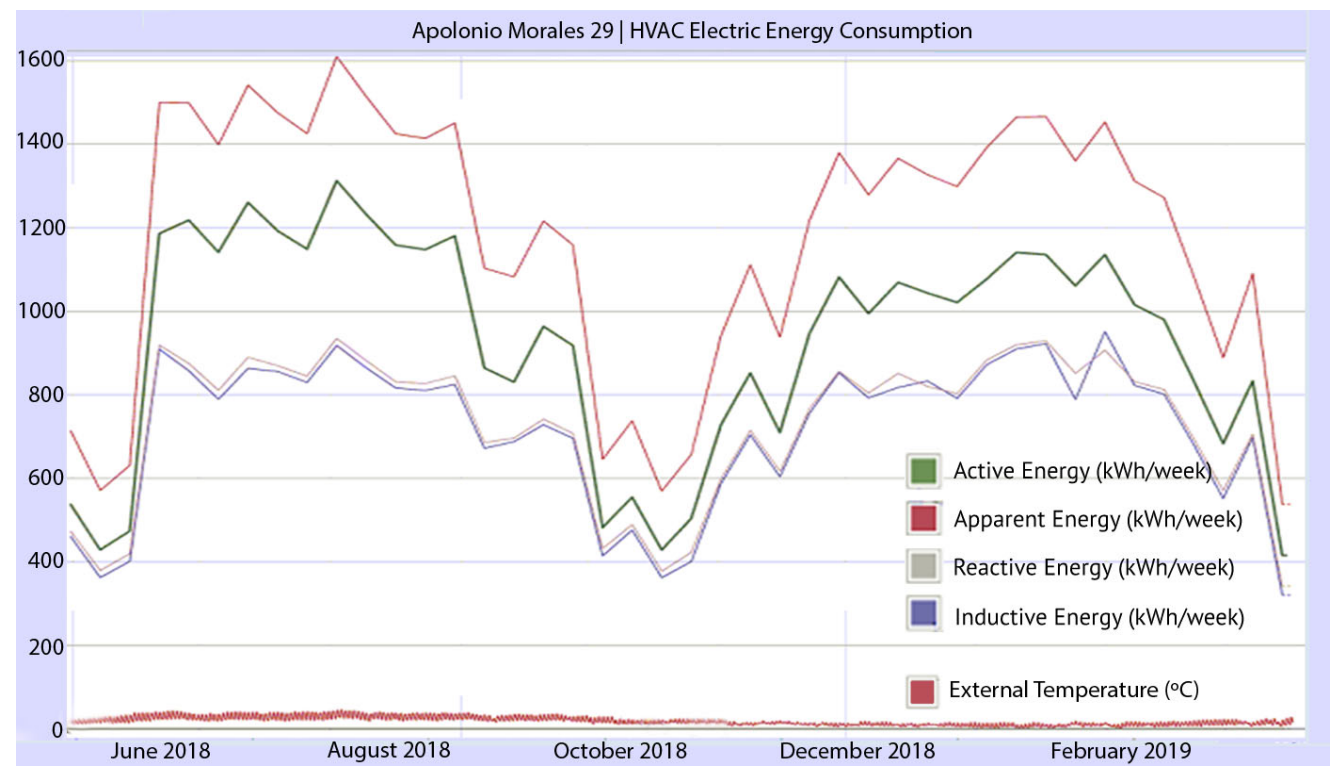

Figure 6. HVAC Electric Energy Consumption. Period: June 2018 - May 2019

(source: Apolonio Morales 29, Madrid, Control System, Building Operation WorkStation 1.4.1.73. Self-elaboration)

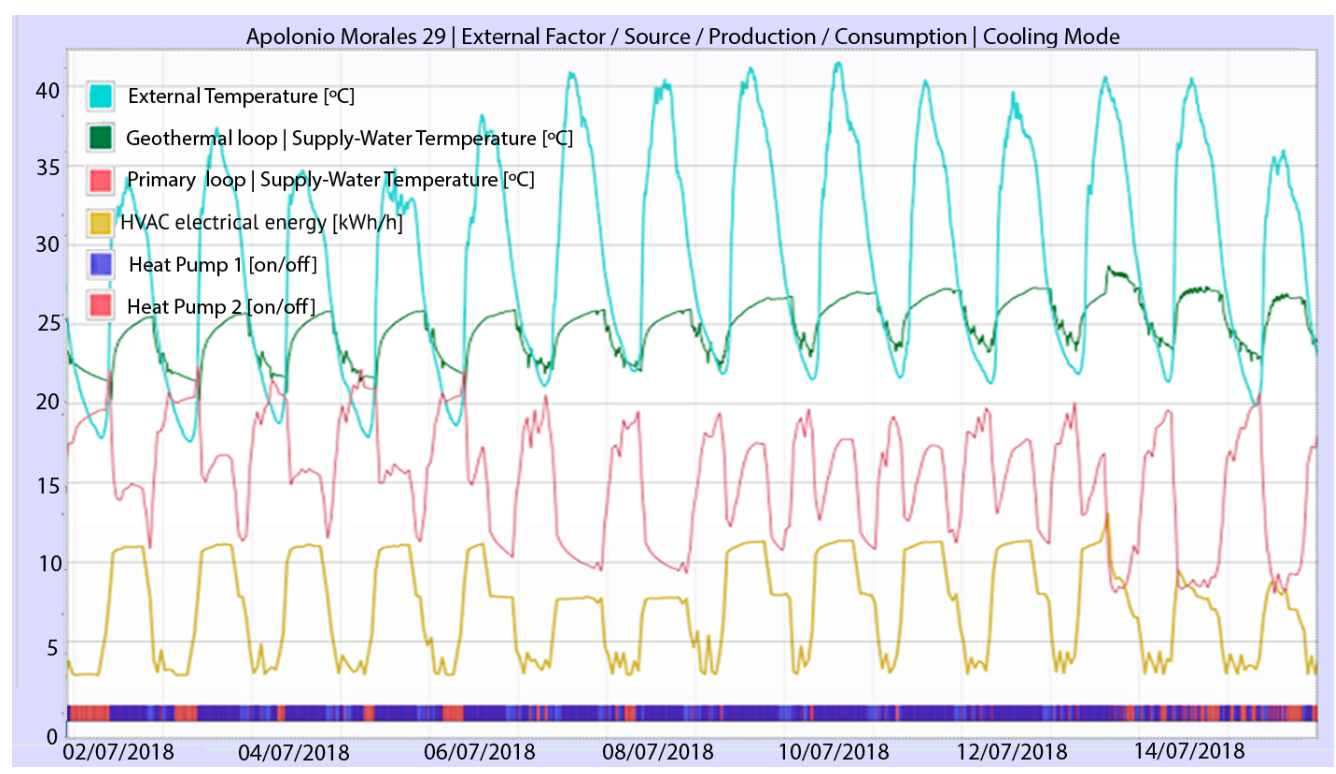

Figure 7. External Factor/Source/Production/Consumption | Cooling Mode. Period: Monday, July 2, 2018 - Sunday, July 15, 2018 (source: Apolonio Morales 29, Madrid, Control System, Building Operation WorkStation 1.4.1.73. Self-elaboration)

The graph draws attention to the electric energy consumption peaks (yellow curve), coinciding with the operation of the AHU, as an auxiliary system, according to its hourly schedule. During the daytime, the AHU runs, with a rapid response, to counteract the demand peak generated by the external temperature rise. It is interesting to observe that the AHU has an evident greater impact on energy consumption in summer (70\%), compared to TABS, whose lower consumption can be appreciated during the nighttime hours (around $3 \mathrm{kWh} / \mathrm{h}$ ). The graph reveals a fault in the "overnight strategy" in summer planned at the design stage for TABS, since the temperature of the fluid in the primary loop varies according to an inverse correlation, depending on the external temperature (Figure 8). Therefore, the water temperature increases during the night and decreases during the day. The consequence is that major consumption is no longer concentrated during the nighttime, but during the daily hours.

A corrective measure consisted in adjusting and fixing the setpoint supply-fluid temperature from a variable value in a range of $9-25^{\circ} \mathrm{C}$ (Figure 8) to $18{ }^{\circ} \mathrm{C}$, via the control system interface. The aim is to exploit TABS cooling capacity with lower fluid temperature during the night, when there is no occupancy in the building, external temperature is lower and energy is more cost-effective. 


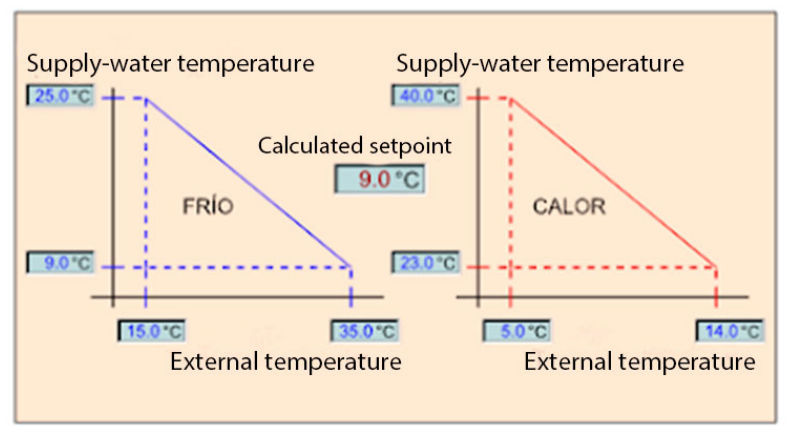

Figure 8. Setpoint Manager: Supply Temperature Control (source: Apolonio Morales 29, Madrid, Control System, Building Operation WorkStation 1.4.1.73)

The excessive AHU operation in summer is also justified with a higher cooling energy demand on the last floor, principally due to its sun exposure and a direct relationship with the roof: this floor is thermally conditioned by only one thermoactivated slab, instead of two as the rest of the floors (the floor section does not include any insulation layer) (Figure 9). Moreover, although TABS can be associated to radiant systems, their operation produces convection effects, which are minimized on the last floor of the building in cooling mode.

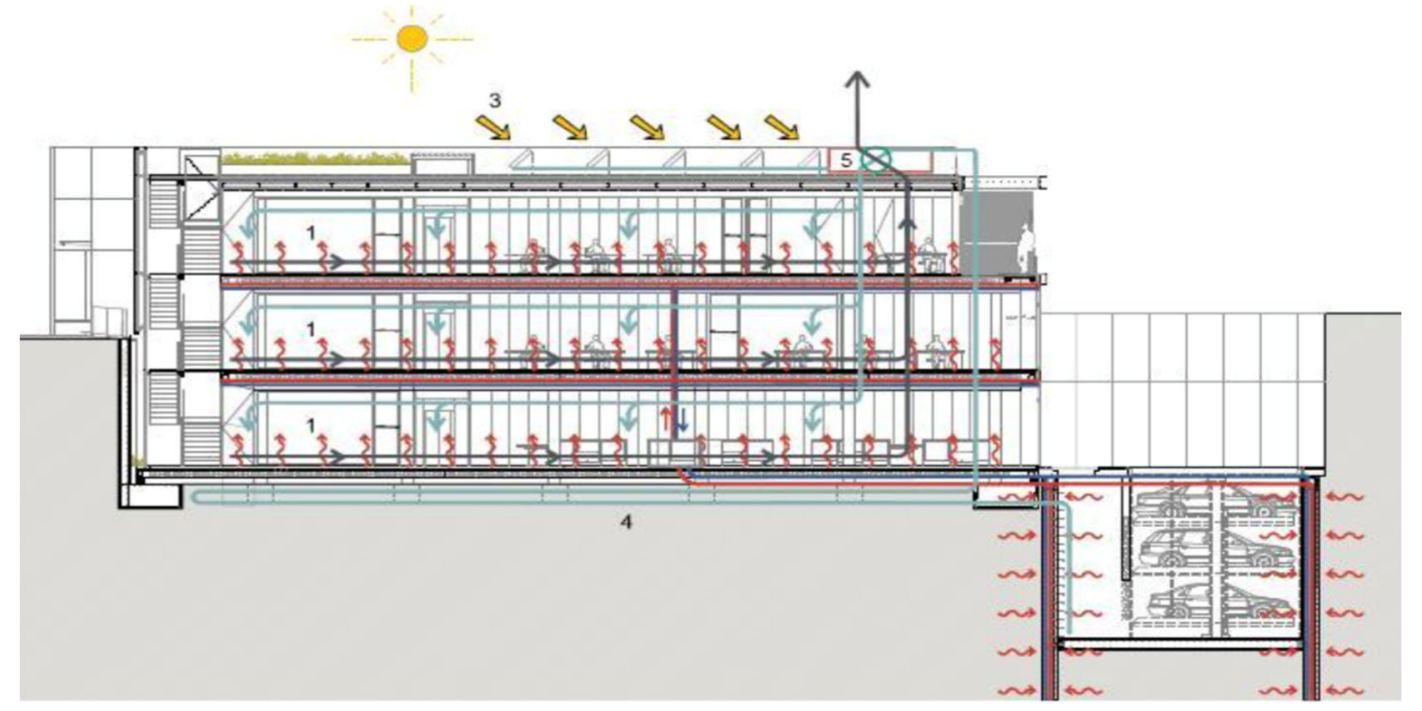

Figure 9. HVAC system. Longitudinal section. Apolonio Morales 29, Madrid (source: IEI Instituto Europeo de Innovación)

The effects are depicted in Figure 10: room temperature on the last floor (blue curve) is always above its corresponding setpoint in summer (red curve), thus the valve is constantly open (grey bars) to enable the circulation of water in the floors for cooling.

Actually, $100 \%$ of the roof is hit by direct radiation, which means it is acting as a "solar collector". The roof, which is exposed to solar radiation during most hours of the day, would have required a heavy construction with a long-time lag. However, although a thermoactivated roof could ensure very good thermal conditions in summer, it is usually expensive to construct such massive roofs (Balaras, 1996), especially when it comes to building retrofitting. In Apolonio Morales, the original roof structure was preserved and was solved with an inverted solution including an additional insulation and anti-radiation barrier.

The main method to compensate this inefficiency on the first floor, consists of programming, specifically for this zone, different setpoint room temperature values, higher in winter and lower in summer, compared to the rest of the zones. Moreover, a well-sized and sectoralized use of the AHU for this floor would contribute to moving air to make up for the lack of convective effects in summer.

In December 2018, another corrective measure was applied, at envelope level, as a contribution to minimize that inefficiency: white gravel with SRI 90, was laid to cover a large part of the roof surface, with the aim to improve the reflectance of the roofing materials. Using materials with a high solar reflectance index (SRI) contributes to lower roof and indoor temperatures (U.S. Green Building Council, 2009). In this regard, it represents an opportunity to increase savings on air conditioning in summer. At the end of summer 2019, the benefits in terms of energy savings and thermal comfort will be quantifiable. 


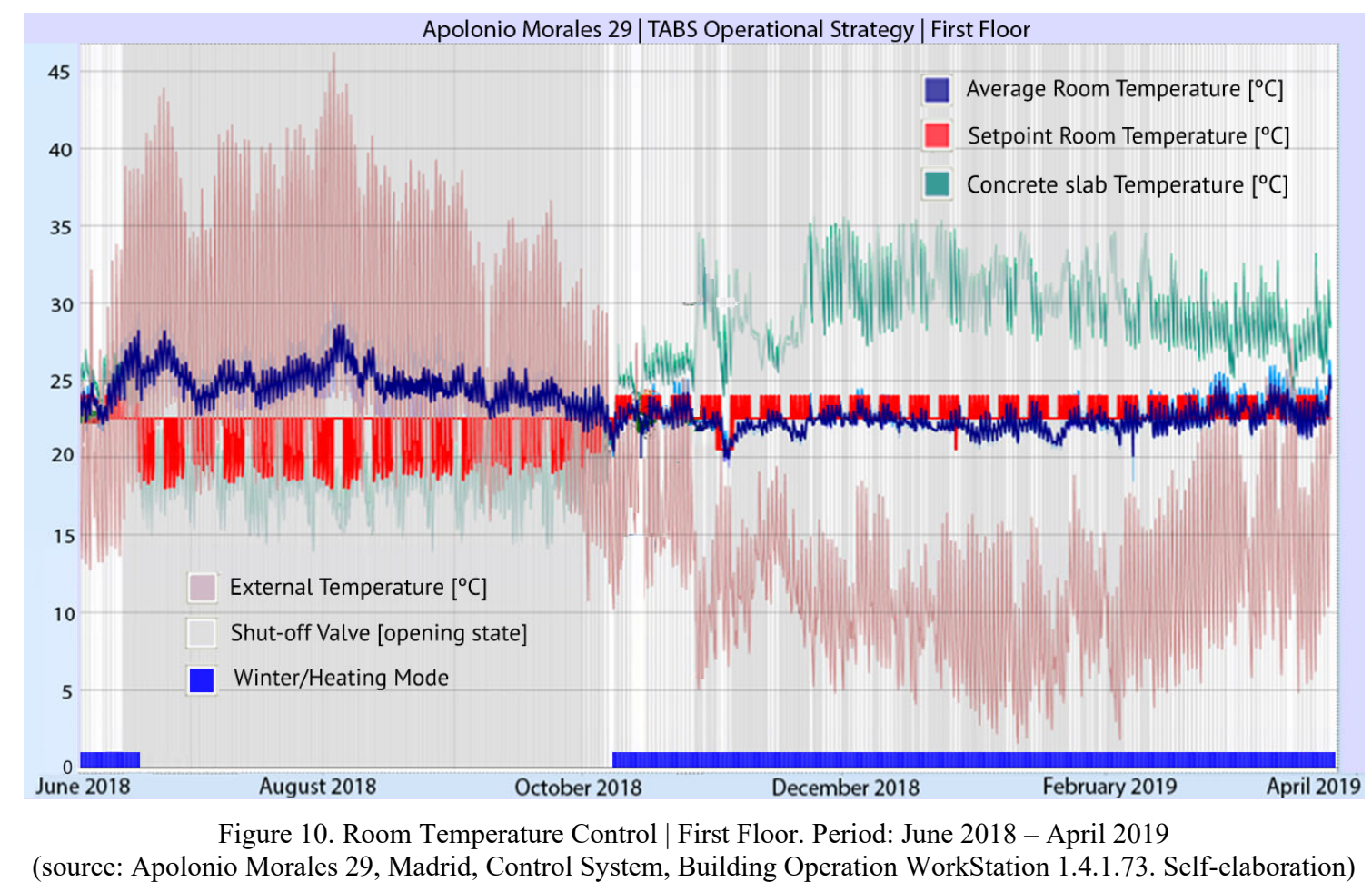

\section{Conclusions}

Appropriate integration of inertial elements, in the frame of a comprehensive renovation process, ensures uniform temperatures and energy savings, thanks to their storage capacity. In the design process and recovery of existing building elements, TABS require proper solutions and management arrangements. Moreover, operational strategies for TABS should be assessed in relation to the storage capacity of the materials involved in the thermal activation and their combination.

TABS integration in existing buildings may present some peculiarities or limitations, that could also affect their performance. In this respect, proper methodologies of energy management and follow-up, specific control strategies and solutions are shown in this paper, and are designed for the improvement of building energy efficiency from the thermal activation of existing structures.

It is well-known that mechanical ventilation systems come to the aid of TABS, counteracting peaks in energy demand with a rapid response (Kephalopoulos, Geiss, Barrero-Moreno, D’Agostino, \& Paci, 2016). In a building equipped with TABS, the efficient control of their operative parameters and setpoints contributes to increasing or decreasing the thermal charges in slab floors. As Figueroa et al. (2018) state in their research, this evidently contributes to minimizing the consumption for air conditioning in summer, while reducing the size of the ventilation systems to provide acceptable Indoor Air Quality (IAQ) or the necessary heating or cooling at peak times.

Moreover, a systematic control of TABS operation, which takes account of their inertial response, occupant feedback, internal gains and boundary conditions, could have positive effects on both the indoor air quality and consumption, during the summer and winter periods. Significant energy savings could be achieved applying appropriate solutions, control strategies and corrective actions. A systematic audit needs to be conducted, aiming at the optimization of TABS energy performance in building retrofitting. Monitoring and analyzing parameter trends and charts, specifically created according to particular criteria, are useful to draw up new action strategies and identify specific criticality or issues, that are causes of abnormal consumption.

The continuity of energy diagnosis and energy management has been proven necessary to keep high standards in terms of TABS energy performance, especially with reference to the renovation and exploitation of existing buildings. The correction of deficiencies and the identification of energy saving opportunities are keys to achieving high levels of energy efficiency, while ensuring acceptable thermal comfort conditions for the occupants.

\section{Acknowledgements}

This paper is part of work carried out in the framework of an agreement between ENERES, the research group "Seminario de Construcción y Ecología (SCE)" of the Universidad Politécnica de Madrid, and Politecnico di Bari (DICATECh). It was supported by ENERES; the consortium "Best Erasmus Traineeships for Jobs"; and "TUCEP (Tiber Umbria Comett Education Programme)". 
Laera, R.; Martínez Pérez, I.; de Pereda Fernández, L.; Tendero Caballero, R.; Iannone, F. 2019.

The role of Thermally Activated Building Systems (TABS) in building energy retrofitting: energy diagnosis and management

\section{References}

Aydin, D., Casey, S. P., \& Riffat, S. (2015). The latest advancements on thermochemical heat storage systems. Renewable and Sustainable Energy Reviews, 41, 356-367. https://doi.org/10.1016/j.rser.2014.08.054

Balaras, C. A. (1996). The role of thermal mass on the cooling load of buildings. An overview of computational methods. Energy and Buildings, 24, 1-10. https://doi.org/10.1016/0378-7788(95)00956-6

De Pereda Fernandéz, L. (2014). Intergración de sistemas termoactivos para eficiencia. Principios y casos. In Guia sobre estructuras termoactivas y sistemas inerciales en la climatización de edificios (pp. 107-145), Fundación de la Energía de la Comunidad de Madrid (FENERCOM). Madrid. Retrieved from https://www.fenercom.com/pages/publicaciones/publicacion.php?id=208

De Pereda Fernandéz, L. (2015). Type of action to improve energy efficiency in the full renovation of a small palace protected Administration office in Madrid. Geothermal and thermoactive structures. - Modelo de actuación para la mejora de la eficiencia energética en la Rehabilitación Integral de un palacete protegido para oficinas de la Administración en Madrid. Geotermia y estructuras termoactivas. Anales de Edificación, 1(2), 1-9. https://doi.org/10.20868/ade.2015.3099

European Commission. (n.d.). Energy, topics, energy efficiency, buildings. Retrieved from https://ec.europa.eu/energy/en/topics/energy-efficiency/energy-performance-of-buildings Last access 27/04/2019

European Union. (2012). Directive 2012/27/EU of the European Parliament and of the Council of 25 October 2012 on energy efficiency (Article 2). Retrieved from https://eur-lex.europa.eu/legal-content/EN/TXT/?uri=celex\%3A32012L0027

European Union. (2014). Statistical pocketbook 2014. Retrieved from https://ec.europa.eu/transport/facts-fundings/statistics/pocketbook-2014_en

Figueroa, I. C., Cigler, J., \& Helsen, L. (2018, April 23). Model predictive control formulation: a review with focus on hybrid geotabs buildings. In Proceedings of the REHVA Annual Meeting Conference Low Carbon Technologies in HVAC, Brussels.

Gómez, M. (2017, May 2). Level II Analysis of Apolonio Morales office building. El Masnou (Barcelona, Spain).

Gwerder, M., Todtli, J., Lehmann, B., Renggli, F., \& Dorer, V. (2007). Control of thermally activated building systems. In Proceedings of Clima 2007 WellBeing Indoors. Retrieved from http://www.irbnet.de/daten/iconda/CIB8370.pdf

Helsen, L. (2016). 15 - Geothermally activated building structures. In S. J. Rees (Ed.), Advances in ground-source heat pump systems (pp. 423-452). Woodhead Publishing. https://doi.org/10.1016/B978-0-08-100311-4.00015-7

IEA. Energy Technology Perspectives. (2012). Pathways to a clean energy system. Retrieved from https://www.iea.org/publications/freepublications/publication/ETP2012 free.pdf.

Kephalopoulos, S., Geiss, O., Barrero-Moreno, J., D’Agostino, D., \& Paci, D. (2016). Promoting healthy and energy efficient buildings in the European Union - National implementation of related requirements of the Energy Performance Buildings Directive (2010/31/EU). European Commission, Science and Knowledge Service, Brussels, Belgium.

Lehmann, B., Dorer, V., Gwerder, M., Renggli, F., \& Tödtli, J. (2011). Thermally activated building systems (TABS): energy efficiency as a function of control strategy, hydronic circuit topology and (cold) generation system. Applied Energy, 88, 180191. https://doi.org/10.1016/j.apenergy.2010.08.010

Lim, J. H., Song, J. H., \& Song, S. Y. (2014). Development of operational guidelines for thermally activated building system according to heating and cooling load characteristics. Applied Energy, 126, 123-135. https://doi.org/10.1016/j.apenergy.2014.03.087

Pfafferott, J., Doreen, K., \& Koenigsdorff, R. (2015). Bauteilaktivierung: Einsatz - Praxiserfahrungen - Anforderungen. Stuttgart: Fraunhofer IRB Verlag.

Rodriguez-Ubinas, E., Montero, C., Porteros, M., Vega, S., Navarro, I., Castillo-Cagigal, M., Matallanas, E., \& Gutiérrez, A. (2014). Passive design strategies and performance of Net Energy Plus Houses. Energy and Buildings, 83, 10-22. https://doi.org/10.1016/j.enbuild.2014.03.074

Romaní, J., de Gracia, A., \& Cabeza, L. F. (2016). Simulation and control of thermally activated building systems (TABS). Energy and Buildings, 127, 22-42. https://doi.org/10.1016/j.enbuild.2016.05.057

Saheb, Y., Bódis, K., Szabó, S., Ossenbrink, H., \& Panev, S. (2015). Energy renovation: the trump card for the new start for Europe (JRC Science and Policy Reports). Luxembourg: Publications Office of the European Union.

Schmelas, M., Feldmann, T., \& Bollin, E. (2017). Savings through the use of adaptive predictive control of thermo-active building systems (TABS): a case study. Applied Energy, 199, 294-309. https://doi.org/10.1016/j.apenergy.2017.05.032

Tödtli, J., Gwerder, M., Lehman, B., Renggli, F., \& Dorer, V. (2009). TABS-control: Steuerung und regelung von thermoaktiven bauteilsystemem. Faktor Verlag Zurich, Switzerland. https://doi.org/10.1002/bapi.200910042

U.S. Green Building Council. (2009). Green Building Operations and Maintenance. LEED Reference Guide for Green Building Operations and Maintenance. For the Operations and Maintenance of Commercial and Institutional Buildings.

Velasco Gómez, E., Andrés Chicote, M., Rey Martínez, F. J., \& Tejero González, A. (2017, August 21-24). Thermal behaviour of an active slab: experimental study for TABs applications. Energy Procedia, 142, 3326-3331. https://doi.org/10.1016/j.egypro.2017.12.465 